\title{
Visual and tactual interaction in judgments of the vertical
}

GARY KRESS and JOHN CROSS, Saint Louis University, St. Louis, Mo. 6.310 .3

Four field-dependent and four field-independent Ss set a comparison bar to the apparent vertical while receiving either veridical or nonveridical reference information. Two intramodal and two intermodal conditions were used. Visual settings were significantly more accurate than tactual settings regardless of the reference modality used. The visual reference significantly increased the error of the tactual setting over that using a tactual reference. The differences between the groups w'ere not statistically significant. The nature of the intermodal interaction needs further clarification.

A series of previous studies by Witkin \& Asch (1948a, b) demonstrated that the vertical position of a bar could be judged very accurately through the visual modality both in the absence of any visual field and in the presence of an upright field. They discovered that, as the visual field is tilted, some Ss increase their errors in the direction of the tilt while others continue to make accurate judgments. This apparent influence of the visual field on some Ss was labeled field-dependence and the nonadherence field-independence.

In recent years a number of investigators have been collecting data on the effect of the visual and haptic modalities working together in different spatial orientation and form-discrimination tasks. Rock \& Victor (1964), using distorting lenses, found that Ss tended to follow false visual information rather than accurate tactile information when asked to judge the size and shape of an object which they viewed and felt simultaneously. Cashdan (1968) also paired visual and tactual inputs and reported that Ss perform best on a visual intramodal task. On the other hand, Legge (1965) used a spatial positioning task and found that visual settings were more accurate than tactual settings and that intermodal information processing produced greater errors than intramodal.

The evidence seems to indicate that the visual modality is superior to the tactual modality when they are examined separately. When the two are combined in the same task, however, the outcome is not so clear.

The purpose of the present study was twofold: first, to investigate the relative accuracy of the visual and tactual modalities used either alone or together in making judgments of the true vertical, and secondly, to determine whether field-dependence could be demonstrated in situations involving comparable visual and tactual tasks.

\section{SUBJECTS}

The Ss used were eight male student volunteers from Saint Louis University. The Ss were selected from a group of 60 on the basis of their scores on a modification of the Embedded-Figures Test which has been identified as a measure of field-dependence (Witkin, 1962). The four who scored highest were labeled field-independent and the four with the lowest scores were named field-dependent. All Ss were right-handed and had no known visual or motor defects.

\section{APPARATUS}

The apparatus consisted of a rectangular box which enclosed two 6-in. luminous (black light) wooden rods, 8 in. apart at their centers. The box and the rods were mounted at eye level to a seated $S$ in a darkroom. The shafts on which the rods pivoted were fastened to pointers on the other side of the wall. There $\mathbf{E}$ could take readings of the position of the rods to the nearest $1 / 4 \mathrm{deg}$. A flap in the box was controlled by $\mathrm{F}$. allowing $S$ to see one, both, or neither of the stimulus rods. The $S$ could reach inside the box through the open bottom for easy manipulation of one or both of the rods. The S's task was to set the rod designated by $E$ to the true vertical while receiving information from the reference rod.

\section{PROCEDURE}

All Ss were instructed that their task was always to set the rod designated by $\mathrm{E}$ to the true vertical either visually or tactually. The vertical was defined as the position of a plumb line with respect to gravity.

The variables investigated were: (1) setting conditions, i.e., visual reference-visual setting $(\mathrm{V}-\mathrm{V})$, visual reference-tactual setting (V-T), tactual reference-visual setting (T-V), tactual reference-tactual setting (T-T); and (2) the effect of the reference rod at either 0,4 , or $15 \mathrm{deg}$ from the true vertical. The Ss were told that sometimes the reference rod would be at the true vertical and sometimes it would not; they were to use it as they thought appropriate. A counterbalanced design was used to control for learning and starting position effects. After 24 settings which combined four setting conditions, threc reference bar positions, and starting position of the comparison bar left or right, the $S$ s repeated the settings, starting with the last one first for a total of 48 settings. In addition all Ss made four visual and four tactual settings without the use of a reference to establish a base line. The $S$ manipulated the rod himself for the tactual settings and $\mathrm{l}$ : adjusted the rod to the $S$ 's satisfaction for the visual settings.

The data were assimilated in a 2 (Groups) by 3 (Reference Rod Position) by 4 (Setting Conditions) factorial design with repeated measures.

\section{RESULTS}

Figure 1 shows the mean errors for all Ss with the reference rod positioned at 0,4 , and $15 \mathrm{deg}$. The mean error for visual and tactual settings made alone without a reference rod are indicated by the dot and the triangle. The tactual settings ( $\mathrm{V}-\mathrm{T}$ and $T-T$ ) produced greater errors than the visual settings ( V-V and $T-V)$. The analysis of variance showed a significant main effect for the four conditions $(F=11.77$, $\mathrm{df}=3, \mathrm{p}<.001)$.

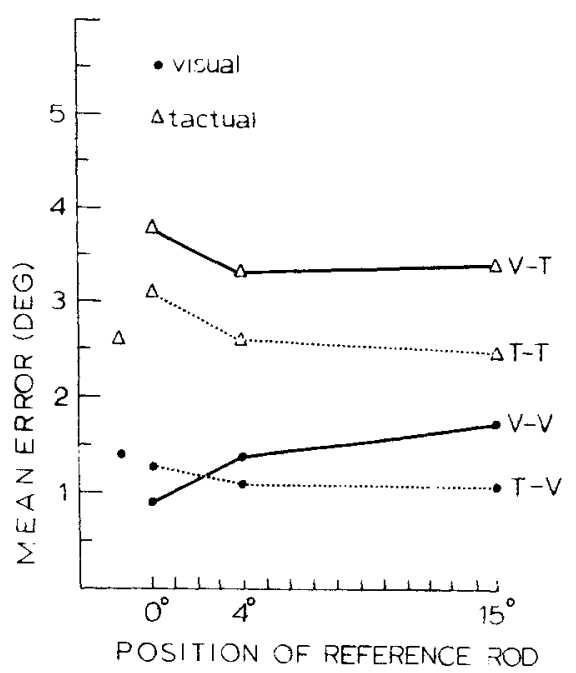

Fig. 1. Mean error for all Ss as a function of conditions and position of the reference rod. 


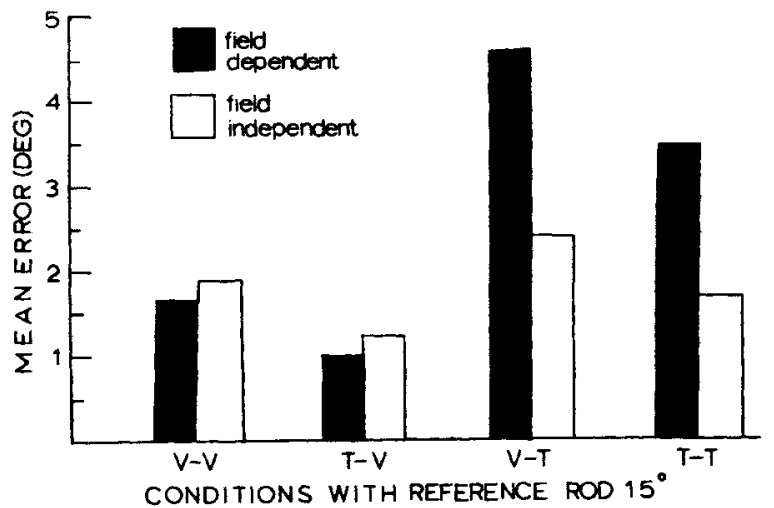

Fig. 2. Mean error compared for field-dependent and fieldindependent Ss as a function of conditions with the reference rod at $15 \mathrm{deg}$.

The main effects for $\mathbf{S}$ groups and reference rod position were not significant. Pair comparisons of all conditions were statistically significant $(p<.05)$ except in the case of the visual settings.

The data shows that visual settings were significantly more accurate than tactual settings regardless of the reference modality. The intermodal V-T condition produced significantly greater errors than all other conditions, indicating that a visual reference has a considerable influence on a tactual setting.

Figure 2 shows the mean errors of the subject groups in all the conditions with the reference rod at $15 \mathrm{deg}$. Although there was not a statistically significant difference between the groups, the trend of the data show that the field-dependent Ss produced greater errors for the tactual settings only. If field-dependence is simply an adherence to prevailing stimulus input then the visual settings should have been influenced also by the inaccurate (15-deg) input.

\section{DISCUSSION}

The results of this experiment support earlier findings concerning the superiority of the visual modality. The settings made visually were consistently better than the tactual settings and cross-modal inputs did not significantly effect the visual settings. On the other hand, the data show that not only were tactual settings more inaccurate but that visual reference, accurate or not, increased this error. It seems that the mediating processes involved in translating visual information into tactual outputs detracted from the accuracy of the tactual modality working alone. This is consistent with Legge's (1965) study cited above. Contrary to Legge, however, the T-V intermodal condition was the most accurate. It appears that nonvertical tactual reference information was recognized as such and exerted no influence on the visual settings.

The conditions with the reference rod at $15 \mathrm{deg}$ from the vertical were expected to produce the greatest difference between the subject groups. In the visual settings there was a similarity in performance of the field-dependent and field-independent Ss. This similarity could be accounted for by the fact that the Ss were not compelled by a visual "field." In the Witkin situations of tilting room, rod and frame, and embedded figures a visual figure-ground relationship was involved. In the present conditions the visual situation was more one of multiple figures than of figure-ground which could account for the different results reported here.

The present findings, therefore, are consistent with previous research suggesting that the visual modality plays a dominant role in verticality judgments. The nature of the intermodal interaction between visual and tactual modalities, however, needs further investigation to determine if there is a consistent way in which they interact.

\section{REFERENCES}

CASHDAN, S. Visual and haptic form discrimination under conditions of successive stimulation. Joumal of Experimental Psychology, 1968, 76, 221-224.

LEGGE, D. Analysis of visual and proprioceptive components motor skil by means of drug. British Journal of Psychology, 1965, 56, 243-254. ROCK, I., \& VICTOR, J. Vision and touch. Science, 1964, 143, 594-600. WITKIN, H. A., DYK, R. B., FATERSON, H. F., GOODENOUGH, D. R., \& KARP, S. A. Psychological differentiation, New York: John Wiley \& Sons, 1962.

WITKIN, H. A., \& ASCH, S. E. Studies in space orientation: III. Perception of the upright in the absence of a visual field. Joumal of Experimental Psychology, 1948a, 38, 603-614.

WITKIN, H. A., \& ASCH, S. E. Studies in space orientation: IV. Further experiments on the perception of the upright with displaced visual fields. Journal of Experimental Psychology, 1948b, 38, 762-782.

\section{ERRATA}

ROECKELEIN, JON E. Simplicity as a principle in tactual form perception. Psychonomic Science, 1968, 13 (4), 195-196.-On page 196, 1st column, the 23rd line should read ". . . "complex" stimuli as "simple" less often than did Group 2 . . ."

HILL, J. H., \& LIEBERT, R. M. Effects of consistent or deviant modeling cues on the adoption of a self-imposed standard. Psychonomic Science, 1968, 13 (4), 243-244.-Lines 3-5 of the Discussion on page 244 are incorrect. They should read, ". . . quite precise adherence to the stringent standard. In keeping with the direct instruction which they received and the models whom they saw, Ss in these groups selfadministered ...." 